\title{
Moving apart together: co-movement of a symbiont community and their ant host, and its importance for community assembly
}

\author{
T. Parmentier ${ }^{1,2^{*}}$ (D) R. Claus ${ }^{1}$, F. De Laender ${ }^{2}$ (D) and D. Bonte ${ }^{1}$ (D)
}

\begin{abstract}
Background: Species interactions may affect spatial dynamics when the movement of one species is determined by the presence of another one. The most direct species-dependence of dispersal is vectored, usually crosskingdom, movement of immobile parasites, diseases or seeds by mobile animals. Joint movements of species should, however, not be vectored by definition, as even mobile species are predicted to move together when they are tightly connected in symbiont communities.

Methods: We studied concerted movements in a diverse and heterogeneous community of arthropods (myrmecophiles) associated with red wood ants. We questioned whether joint-movement strategies eventually determine and speed-up community succession.

Results: We recorded an astonishingly high number of obligate myrmecophiles outside red wood ant nests. They preferentially co-moved with the host ants as the highest densities were found in locations with the highest density of foraging red wood ants, such as along the network of ant trails. These observations suggest that myrmecophiles resort to the host to move away from the nest, and this to a much higher extent than hitherto anticipated. Interestingly, functional groups of symbionts displayed different dispersal kernels, with predatory myrmecophiles moving more frequently and further from the nest than detritivorous myrmecophiles. We discovered that myrmecophile diversity was lower in newly founded nests than in mature red wood ant nests. Most myrmecophiles, however, were able to colonize new nests fast suggesting that the heterogeneity in mobility does not affect community assembly.
\end{abstract}

Conclusions: We show that co-movement is not restricted to tight parasitic, or cross-kingdom interactions. Movement in social insect symbiont communities may be heterogeneous and functional group-dependent, but clearly affected by host movement. Ultimately, this co-movement leads to directional movement and allows a fast colonisation of new patches, but not in a predictable way. This study highlights the importance of spatial dynamics of local and regional networks in symbiont metacommunities, of which those of symbionts of social insects are prime examples.

Keywords: Ant guest, Co-dispersal, Community coexistence, Host-parasite, Inquiline, Metacommunity, Spatial structure, Succession

\footnotetext{
* Correspondence: thomas_parmentier@msn.com

'Terrestrial Ecology Unit (TEREC), Department of Biology, Ghent University, K.L. Ledeganckstraat 35, B-9000 Ghent, Belgium

${ }^{2}$ Research Unit of Environmental and Evolutionary Biology, Namur Institute of Complex Systems, and Institute of Life, Earth, and the Environment,

University of Namur, Rue de Bruxelles 61, 5000 Namur, Belgium
}

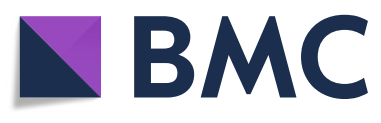

(c) The Author(s). 2021 Open Access This article is licensed under a Creative Commons Attribution 4.0 International License, which permits use, sharing, adaptation, distribution and reproduction in any medium or format, as long as you give appropriate credit to the original author(s) and the source, provide a link to the Creative Commons licence, and indicate if changes were made. The images or other third party material in this article are included in the article's Creative Commons licence, unless indicated otherwise in a credit line to the material. If material is not included in the article's Creative Commons licence and your intended use is not permitted by statutory regulation or exceeds the permitted use, you will need to obtain permission directly from the copyright holder. To view a copy of this licence, visit http://creativecommons.org/licenses/by/4.0/. The Creative Commons Public Domain Dedication waiver (http://creativecommons.org/publicdomain/zero/1.0/) applies to the data made available in this article, unless otherwise stated in a credit line to the data. 


\section{Background}

Species interact via local and regional interactions in spatially structured networks $[1,2]$. Dispersal is a central instigator of community assembly and species coexistence in these networks when it affects species interactions across space [3]. Dispersal is a three-stage process [4] comprising departure, transfer and settlement decision making. The importance of interspecific interactions has been especially documented for departure [5] and settlement [6], but it is equally important for transfer. This is particularly evident for vectored dispersal, where the transport of one species directly depends on another one, usually cross-Kingdom. Organisms or their propagules can thus be passively transported by other organisms as observed in zoochory and ectoparasitism $[7,8]$. Highly advanced symbionts, for instance lichens, coral-dinoflagellate associations and some ant-symbiont associations [9-12] also passively co-disperse with their host as joint propagules.

Many organisms do not passively hitchhike, but actively follow other species guided by sensory cues provided by other species. This strategy is present in diverse groups encompassing microbes that use fungal networks as highways [13], fishes in coral reefs [14, 15] and birds that form foraging associations with other birds $[16,17]$ or co-forage with mammals [18]. Ultimately, these actively following organisms may co-disperse with other organisms and co-colonize new sites, and thereby have strong ecological and evolutionary implications [13, 19] for the structure and functioning of metacommunities [20]. Heterospecific attraction for instance leads to substantial deviations from predicted coexistence processes under strict competition [21].

If we aim to understand species dynamics in realistic metacommunities, we need to collect information beyond emigration probabilities and study the distance decay of movement. Such data are typically summarised in the form of the movement kernels that represent the frequency or probability distribution of movement distance in relation to the place where individuals were born and had their home range. The shape of these kernels is known to be condition dependent. That is, intraspecific interactions such as avoidance of crowding or kin competition may affect these kernels [22]. It will eventually determine the colonisation of new patches within the network, but also range expansion capacities [23]. In classic competition models, the moments of these kernels can influence the prevalence and weight of spatial coexistence mechanisms [24].

Ant nests house a diverse assemblage of arthropod species, so-called myrmecophiles [25]. These myrmecophiles span different functional groups, ranging from detritivores, scavengers, brood predators and species that prey on other myrmecophiles [26]. Ant-myrmecophile associations have been an exquisite model to study different facets of symbiosis [27, 28] and are increasingly explored in a community context [29-31]. This approach enables the comparison of disparate trait syndromes in co-habiting symbionts and are essential to understand their coexistence and the underlying community assembly rules [32]. From the perspective of the symbionts, ant nests are spatially distinct patches in a hostile environment, with age of the nest and the associated community structure determining its suitability in terms of fitness. Ant symbiont networks are thus spatially structured, and to some degree spatially heterogeneous [33, 34], opening avenues for all metacommunity dynamics to act [35]. The behaviour of myrmecophiles outside the nest and colonization events are poorly addressed. There are few anecdotal observations of myrmecophiles outside permanent ant nests [10, 36-40], but myrmecophiles are typically found in ant nests or at nest entrances. Therefore, it is generally assumed that myrmecophiles mostly reside in these nests and only leave the nest at specific events to colonize new nests [10]. Several lab studies demonstrated that myrmecophiles can follow their host by running on the chemical pheromone trails of the ant host [41-45]. Yet, it is unknown whether the trail network of the host facilitate the movement of the symbionts outside the nest and initiate co-dispersal of ants and myrmecophiles towards new nests in a natural setting. In addition to running, many myrmecophiles possess wings and may leave the nest by flying. Specific lineages of myrmecophiles such as mites may also travel outside the nest attached to the host (phoresy) and some are even carried by the host [25].

Red wood ants (Formica rufa group) form a group of dominant central-place foraging ants in temperate forests [46]. Their large nests contain an aboveground mound of organic thatch and a network of underground galleries [46]. Red wood ants (RWAs) move in a directed way through the landscape using trail networks. The highest densities of foraging workers outside the nest can be found on and near these trails. The trails connect the nest with trees, where they tend aphids for honeydew. Red wood ant nests may also cooperate and share resources via inter-nest trails [47]. A diverse community of arthropods lives in strict association with RWAs. These myrmecophiles are typically beetles, but other arthropod groups such as spiders and springtails are also represented [48]. Most of them live permanently in the nest, as all life stages are intranidal. We only recorded a handful of individuals outside the ant nests so far, in spite of hours of observations during the past years [49]. Other species have an alternating life cycle with one stage in the nest and the other outside the nest [49]. The main functional trophic groups that can be found in the community are predatory species that feed on other living myrmecophiles, scavengers that feed on prey and ant 
brood and detritivores that mainly feed on organic nest material and fungi [26].

Here, we first investigated and compared the frequency and characteristics of the mobility of macrosymbionts associated with the nests of RWAs on the forest floor. We compared the mobility of the different functional groups in the myrmecophile community. We also tested whether the symbiont community showed directed movement by co-moving with their host along the routes with the highest density of workers. Second, we studied the colonization of newly founded RWA nests by the symbionts and linked these with the observed species-specific patterns in symbiont mobility.

\section{Methods}

\section{Study sites and study organisms}

Our research was performed at two study sites in the North of Belgium, i.e. de Sint-Sixtusbossen, WestVleteren (site WV, $50.885622^{\circ} 2.698785^{\circ}$ ) and de Hoge Dijken, Oudenburg (site OB, 51.173453 ${ }^{\circ}, 3.052895^{\circ}$ ). The WV site holds a polydomous (= multiple mounds/nests) colony of Formica rufa Linnaeus, 1761 distributed over 48 nests (counted in 2019). Polydomous organization is widespread in red wood ants (RWAs) [46]. The polydomous colony is spread over different clusters of nests which are lined along the southern edge of deciduous forest fragments (Additional file 1: Fig. S1). Mounds in the same forest fragment cooperate, exchange food, brood and workers via trails running between the nests. Nests do not interact with nests of other forest fragments, because of physical barriers (e.g., road). Every nest mound contains multiple queens (pers. observations $\mathrm{TP})$. The RWA species in $\mathrm{OB}$ is Formica polyctena Förster, 1850. Formica rufa and F. polyctena are closely related and may hybridize [50]. Their nest structure, behaviour and supported myrmecophilous fauna is similar in north west Belgium $[48,51]$. The nests in $\mathrm{OB}$ (total of 30 nests) are more scattered as the canopy of the forest fragment is more open (Additional file 1: Fig. S1). Additionally, some nests can be found in an adjoining meadow. The social organization in the $\mathrm{OB}$ site is less clear than in WV. It is unknown whether the nests operate independently or exchange resources. No aggression between the mounds was recorded, but clear inter-nest trail networks are absent in this site.

\section{Spatial distribution of myrmecophiles outside the host nest and underlying drivers}

We assessed the spatial distribution of RWA myrmecophiles outside the nest and identified the predictors of the observed patterns. The spatial patterns were assessed using a series of pitfall traps. The densities of workers around ant nests and on the trails are extremely high, which makes classic accumulation pitfalls with a preservative not workable. Therefore, we opted for a pitfall where the ants can easily crawl out, but the myrmecophiles not. We used a plastic box (Sunware Q-Line Box: $27 \times 8.4 \times 9 \mathrm{~cm}$, volume: $1.3 \mathrm{~L}$ ) with a $1 \mathrm{~cm}$ layer of moist plaster on the bottom (Fig. S2a-c). The sides were too slippery for the myrmecophiles to escape from, but ants could easily climb out of these boxes. The rectangular pitfalls were positioned with their long side perpendicular to the direction away from the nest to maximize capture efficiency (see Fig. 1, Fig. S2b and video in Additional file 3). The pitfalls were buried so that their top rim was level with the surface of the soil. We covered pitfalls with a plastic roof to prevent rain falling in. The roof was positioned $2 \mathrm{~cm}$ above the opening of the pitfalls by attaching plastic caps in the corners of the roof. Soil and organic material also fell in the pitfalls (came by the wind or the ants passing by), which provided an ideal temporary habitat for the myrmecophiles (Additional file 3 ). This study was done entirely at the WV-site, where all nests are lined along the forest edge (Additional file 1, Fig. S1). We focused on the distribution of myrmecophiles around twenty pairs of nests formed out of 24 nests. The distance between the nests of each pair greatly varied (range: $1.2 \mathrm{~m}-51.2 \mathrm{~m}$ ). For each pair of nests, we installed seven pitfalls. One pitfall was placed at the midpoint between each pair of nests along the forest edge ('edge pitfall') (Fig. 1). These pitfalls assessed movement of myrmecophiles along the shortest path to the other nest of the pair and were often positioned on an inter-nest trail. Movement along this trajectory was expected to be the preferred direction. We compared this movement direction with the perpendicularly orientated movement away from the forest edge towards the inner forest. Therefore, we placed for each nest of the nest pair a pitfall ('forest pitfall') on a line segment originating from the nest and perpendicular to the shortest inter-nest path. We positioned these pitfalls in such a way that a nest was equidistant from the edge and forest pitfall (Fig. 1). Next, we positioned a pitfall just outside each nest of the nest pair ('periphery pitfall', periphery = $0 \mathrm{~m}$ ). The peripheral zone was discernible from the actual nest by the lack of nest openings and organic material. These pitfalls were not aligned with the other extranidal pitfalls to avoid trapping myrmecophiles before they could reach other extranidal pitfalls. We also burrowed a pitfall inside every nest ('intranidal pitfall') of a focal pair of nests (Fig. 1).

The pitfalls were left for 1 week and then emptied in a large tray in the field. Myrmecophiles were counted and identified to species (beetles following [52, 53] spiders following [54]) and also the number of $F$. rufa workers in the pitfall (including the individuals on the inner walls) was counted. RWA networks are relatively stable over the season, and therefore the number of ants in the 


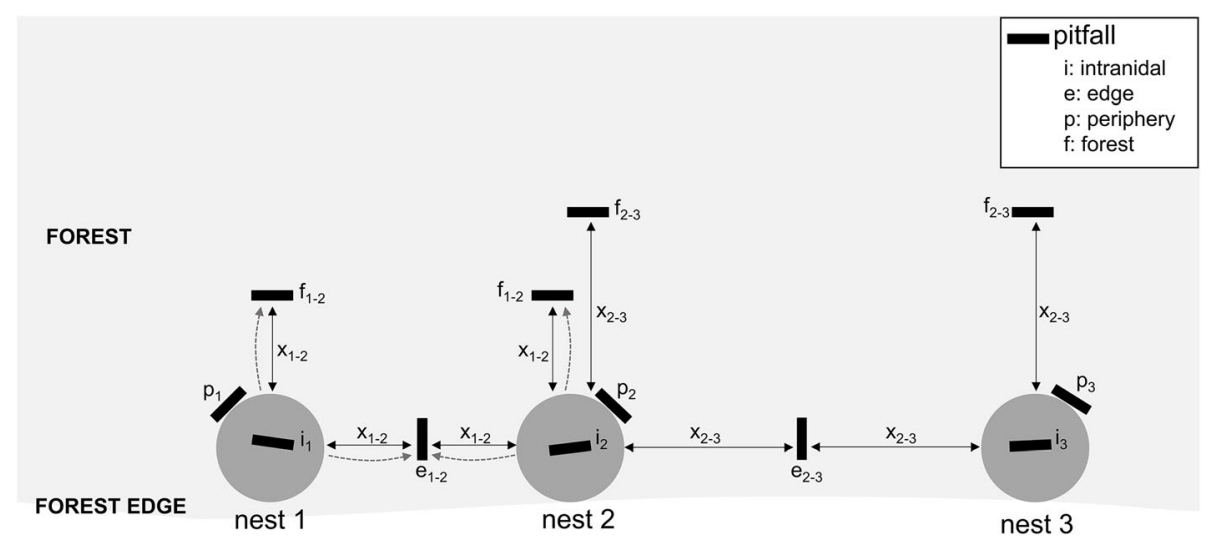

Fig. 1 Schematic diagram of the positioning of pitfalls, here around three nests lined along a forest edge. We sampled the myrmecophiles inside a nest with an intranidal pitfall (i) and at the boundary $(0 \mathrm{~m})$ of a nest with a periphery pitfall (p). We placed an edge pitfall on the midpoint between two nests (along the forest edge direction). The captured myrmecophiles of this pitfall originate from either of the adjoining nests (see arrows). For both nests of this pair, a forest pitfall ( $f$ ) was installed equidistant from the distance to the midpoint. Myrmecophiles found in this type of pitfall were mainly coming from the nearest nest (see single arrow). A nest which lies between two other nests in a forest fragment was part of two pairs of nests (here pair: nest1-nest2 and pair: nest2-nest3). For such a nest, two forest pitfalls were positioned at different distances: one at the half of the distance between nest 1 and 2 (midpoint distance $x_{1-2}$ ), and one at the half of the distance between nest 2 and 3 (midpoint distance $\mathrm{x}_{2-3}$ ). Distance $\mathrm{x}$ varies from 0.6 to $25.6 \mathrm{~m}$ across the 20 tested nest pairs (distribution nests see Additional file 1: Fig. S1)

pitfall at the time of sampling is a good proxy for the general ant activity at that location. Pitfalls were emptied and ants were counted between $11 \mathrm{~h}$ and $15 \mathrm{~h}$ to minimize effects of temperature on the activity of the ants. Pitfalls which were positioned on or near trails were visited by much more workers than pitfalls away from them. We grouped the myrmecophilous species Monotoma angusticollis and Monotoma conicicollis as Monotoma, because they can only be distinguished using a stereomicroscope. We used the same type of pitfalls with roofs to assess the diversity in the nests. As ants gradually fill the pitfall with nest material, these boxes had to be emptied sooner to avoid that the myrmecophiles could escape. We emptied these boxes every 1-2 days and kept the myrmecophiles apart to avoid double counting. After a week, we sampled these boxes a last time and the myrmecophiles that were caught during the week were put back in their nest of origin. In this way, the intranidal sampling effort was similar to the extranidal sampling effort.

The two forest and common edge pitfall were sampled three times (7-day interval between resampling), resulting in nine pitfalls per distance level. The peripheral pitfalls were also sampled three times. Sampling of peripheral, forest and edge pitfalls was organized in 9 time periods: first 5 pairs of nests were checked at 01/ $07,08 / 07$ and $15 / 07 / 2019$, the following 7 pairs of nests at $22 / 07,29 / 07$ and $05 / 08 / 2019$ and the last 8 pairs of nests at 12/08, 19/08 and 26/08/2019. Intranidal pitfalls were only tested once, after the third replicate of each set of nests. A total of 279 pitfalls were emptied (24 intranidal, 75 peripheral, 60 edge and 120 forest pitfalls).
Ants and myrmecophiles were put back after each sampling approximately two meters from the pitfall to avoid that they would directly fall back in the pitfall. We moistened the plaster if needed and put the empty pitfall back in place and did the same sampling protocol for the next replicate.

\section{Spatial distribution of myrmecophiles outside the nest}

In a first analysis, we plotted the distribution of myrmecophiles (abundances and proportion of pitfalls with individuals) along the spatial gradient outside the nest. Next, we compared myrmecophiles and the different functional groups in their tendency to leave the nest, by dividing per species the average number of individuals in an extranidal pitfall $(>0 \mathrm{~m})$ by the average number of individuals in a nest pitfall. The higher the ratio, the higher the tendency to leave the nest. Some myrmecophiles may often leave the nest, but stay very close to the nest entrances. To differentiate this with the tendency to leave the nest, we divided per species the average number of individuals in a peripheral pitfall $(0 \mathrm{~m})$ by the average number of individuals in a nest pitfall. We calculated these ratios for each time period, resulting in nine extranidal and nine peripheral estimates per species. Overall differences among the myrmecophiles in the tendency to leave the nest or to occur at the periphery were assessed using a nonparametric Kruskal-Wallis test, with myrmecophile species as independent predictor. Pairwise comparisons in the tendency to leave the nest or to occur at the periphery between the myrmecophile species were tested using Pairwise Wilcoxon Rank Sum Tests with the BenjaminiHochberg correction for multiple testing [55]. 
In addition, we wanted to test whether myrmecophile species differ in their long-distance movement. For each myrmecophile species, we selected the individuals in the upper decile of the distance distribution outside the nest (periphery not included). Overall differences in longdistance movement among the top movers of the myrmecophiles were tested using a non-parametric KruskalWallis test, with myrmecophile species as independent predictor. Post hoc pairwise comparisons were performed by Pairwise Wilcoxon Rank Sum Tests with the Benjamini-Hochberg correction [55].

\section{Factors affecting the spatial distribution of myrmecophiles outside host nests}

First, we assessed whether the distribution of individual myrmecophile species (i) is inversely related to the distance away from the nearest nest (ii) and positively affected by higher numbers of foraging RWA workers at a given distance outside the nest. The highest number of foraging workers outside the nest is found on and near trails. A positive correlation between ant activity/density and myrmecophile density outside the nest does not automatically imply that the ants affect the movement directions of the myrmecophiles. This association can be the consequence of movement in similar directions away from the nest (for example to shared food patches). However, the distribution of resources outside the nest is very homogeneous for myrmecophiles and hence no directed movement is expected. By contrast, RWAs do show very directed movement outside the nest and preferentially move towards food patches and other nests using trails [46]. In addition, many lab experiments clearly showed that myrmecophiles follow the pheromone trails of their host [41-45]. As such, we expect that the directed movement of myrmecophiles overlapping with the preferred RWA routes, can be explained by the myrmecophiles making use of the host ants and its pheromone network to move outside the nest. Note that myrmecophiles caught outside the nest are not necessarily dispersing to another nest, but may forage as well. For this first set of analyses, we only focused on the peripheral pitfalls $(0 \mathrm{~m}, N=75)$ and the forest pitfalls $(N=120)$ and did not test the directionality of movement (forest vs edge). Per myrmecophile species, we modelled number of individuals found in the pitfalls against the predictors distance from the nearest nest, density of RWA workers in the pitfall and intranidal density in the nearest nest. The latter covariate was included as the number of emigrants was expected to be positively correlated with the intranidal densities. We also included the interaction between distance and density of RWA workers as a predictor. As the models showed overdispersion, we used a negative binomial generalized linear mixed-effect model with poisson error distribution and log link function (glmer.nb function, $\mathrm{R}$ package lme4). The nearest nest of a pitfall and the sampling period were modelled as random factors. We ran these models for the following species: Thyreosthenius biovatus, Stenus aterrimus, Thiasophila angulata, Lyprocorrhe anceps, Notothecta flavipes, Pella humeralis and Cyphoderus albinus. The other species were sparsely recorded outside the nest, so that no model could be fitted. The predictors distance from the nearest nest and intranidal density were square root transformed. Density of RWA workers was incorporated either as a continuous (the square root of the number of workers) or a categorical factor (high density: $>20$ workers, low density $\leq 20$ workers) in separate models (i.e. two models per species). From the full model, we removed with the drop1 function fixed factors which removal did not significantly reduce the explanatory power of the model [56]. In addition, we fitted a similar generalized mixed model to explain total species richness (sum of all myrmecophile species) along the forest spatial gradient. Here we opted for a glmer rather than a glmer.nb as there was no overdispersion. RWA density, distance from the nearest nest and species richness of the nearest nest (square root transformed) were modelled as covariates, sampling period and nearest nest as random factors.

Second, we assessed whether the myrmecophile community preferentially moved along the shortest path to another nest (edge direction). Myrmecophiles travelling along the forest edge follow the shortest path to the nearest nest (the location of all nests is known), as all nests are lined along the forest edge (Fig. 1, Additional file 1, Fig. S1). Myrmecophiles caught in the edge pitfalls between two nests could originate from either of the adjoining nests when they were moving between these nests, whereas peripheral and forest pitfalls mainly capture myrmecophiles from the nearest nest (Fig. 1). To make the sampling effort of the forest pitfalls comparable with the edge pitfalls, we pooled the total number of species over the two inner forest pitfalls per pair of nests. As such, for each pair of nests, we obtained one data point with myrmecophiles caught in the forest and one along the edge at the same distance away from the nests (Fig. 1). Because of the positioning of the nests, the focus here is on nest pairs rather than individual nests. Sampling was replicated three times for each pair of nests. Note that we did not include the data of the peripheral pitfalls (at distance $0 \mathrm{~m}$ ) in these analyses, as directionality of movement could otherwise not be tested.

We modelled the predictors directionality of movement (edge vs forest), distance to the nearest nest and density of RWA workers to predict the response variable species richness (total number of myrmecophile species) using a generalized linear mixed-effect model with Poisson error distribution and log link function. We also 
included the intranidal species richness pooled over a pair of nests as a fourth covariate. Pair of nests and sampling period were modelled as random factors. From the full model, we removed with the drop1 function fixed factors which removal did not significantly reduce the explanatory power of the model [56]. We performed LRtests to assess the significance of the fixed effects in the reduced species richness model.

We validated all models by analyzing their residuals in the DHARMa package [57], but no issues were identified. Significance of the predictors was estimated with a $x^{2}$ Wald (type 3 ) test using the function Anova (car package).

\section{Colonization dynamics of myrmecophiles}

To examine the colonization dynamics of RWA myrmecophiles, we compared the diversity and identity of supported myrmecophiles between well-established, mature nests ("old nests") and newly founded nests ("new nests"). The distribution of RWA mounds in the study sites have been intensely surveyed for the last 20 years [49]. Therefore, we have a clear idea of the age of the mounds in these sites. We selected old (2 sites: OB: $N=$ 4, WV: $N=8$ ) nests which were older than 5 years (mean surface: $4.94 \mathrm{~m}^{2} \pm \mathrm{SE} 0.46$ ). Newly founded nests (2 sites: OB: $N=8, \mathrm{WV}: N=7$ ) arise during spring and were smaller (mean surface: $1.83 \mathrm{~m}^{2} \pm \mathrm{SE}$ 0.32). Sampling was during summer, so these nests were younger than half a year at the time of sampling (Fig. S2d). To avoid lasting damage to the small, new nests, we used noninvasive pitfalls in this experiment (Fig. S2e). They consisted of a plastic $0.5 \mathrm{~L}$ pot (height $7 \mathrm{~cm}$ ) with a $1 \mathrm{~cm}$ plaster bottom and a top opening (diameter $11 \mathrm{~cm})$. The pitfall was filled with wood chips (Pinus maritima, commercially available DCM bark). The myrmecophiles could enter the pitfall through the top opening or through four circular openings (diameter: $1.5 \mathrm{~cm}$ ) that were made at $90^{\circ}$ in the lower part of the pot. In contrast to the pitfalls used in the previous experiment, myrmecophiles were able to exit the pitfall and myrmecophiles were here thus not accumulated over time. We placed a pitfall deep inside the nest with the top rim level with the interface between the aboveground organic material mound and the underground earth nest. The pitfalls were left for 2 weeks in the nest and then checked for myrmecophiles in a large tray in the field. Afterwards, myrmecophiles were put back in the nest and the pitfall with wood chips was re-installed. Every nest was resampled four to six times, with a 14-days interval between each resampling. Sampling took place between the end of June and end of August, either in the summer of 2018 or 2019. Note that colonization here can occur through running on the ground, but also by flying or passive transport (see carrying of Clytra quadripunctata by the host [39]).
We constructed a negative binomial generalized linear mixed-effect model to predict total species richness in a nest as a function of the fixed effects nest age (old vs new), connectivity (the number of mature nests within a $100 \mathrm{~m}$ radius) and site (OB or $\mathrm{WV})$. The first order interactions between the predictors were also modelled. Nest identity was included as a random variable as nests were resampled (4-6 times). From the full models, we removed terms using the drop1 function [56]. We validated this model by analyzing its residuals in the DHAR Ma package [57]. We did not identify residual problems.

All statistical analyses were performed using $\mathrm{R}$ (version 3.4.2).

\section{Results}

\section{Spatial distribution of myrmecophiles outside the host nest}

Myrmecophiles abundant outside host nest, but mobility is functional group-specific

We recorded 3436 obligate myrmecophiles belonging to 17 species (two Monotoma species were grouped) at the periphery and outside the nest of their Formica rufa host. The distribution of myrmecophiles was related to the functional role in the community. Predatory species and, to a lesser extent, scavengers were more mobile and had a higher tendency to reside outside the nest than detritivorous species. The spider Thyreosthenius biovatus and the beetles Monotoma and Clytra quadripunctata were present in most nests and reached high densities in the pitfalls (Fig. 2, Table 1). The rove beetles Stenus aterrimus, Lyprocorrhe anceps and Notothecta flavipes occurred in a higher percentage of pitfalls at the periphery than inside the nest (Fig. 2, Table 1). Most species were captured in a lower percentage of pitfalls and in lower abundances with increasing isolation from the host nest (Fig. 2), but this pattern was not present in the rove beetle Pella humeralis. This beetle was also atypical in the myrmecophile community as it almost exclusively occurred outside the nest.

Myrmecophile species greatly differed in their tendency to occur at the periphery of the nest (Kruskal-Wallis test, chi-squared $=45.39, \mathrm{df}=11, P<0.001$, Fig. 3a, Additional file 1: Fig. S3, Post hoc differences Additional file 2: Table S1). Stenus aterrimus and Q. brevis tend to occur more often at the periphery than other species. Similarly, the average number of individuals in an extranidal pitfall divided by the average number of individuals in a nest pitfall was greatly different among the myrmecophile species (Kruskal-Wallis test, chi-squared $=54.705, \mathrm{df}=11, P<$ 0.001 , Fig. 3b, Additional file 1: Fig. S3, Post hoc differences Additional file 2: Table S2). The detritivores Monotoma, C. albinus and C. quadripunctata had a very low tendency to leave the nest (Fig. 3b, Additional file 1: Fig. S3). Pella humeralis displayed the highest tendency to 


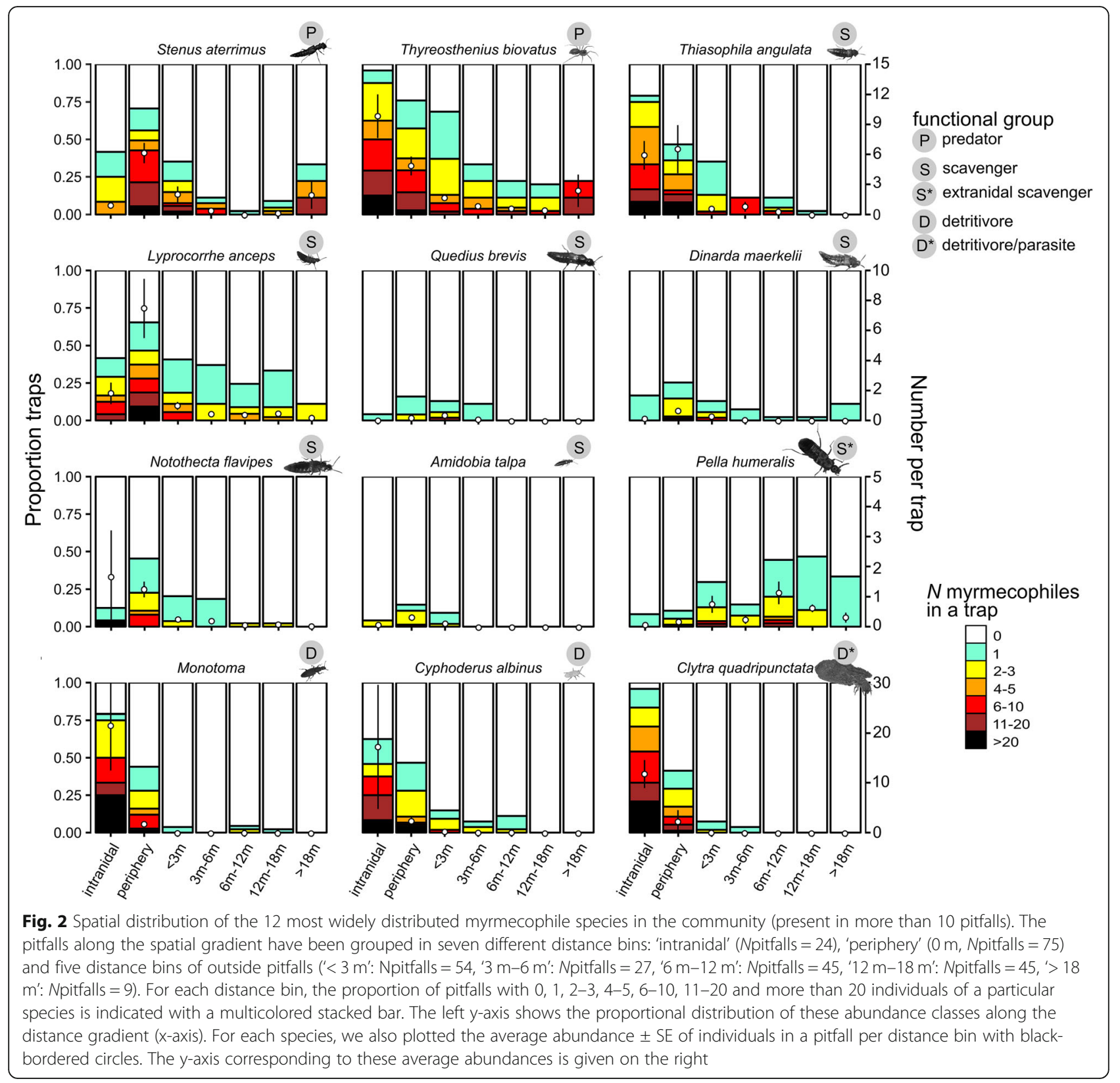

occur outside a nest (Fig. 3b, Additional file 1: Fig. S3). Myrmecophile species differed in the average distance travelled by the individuals at the upper $10 \%$ of their distance distribution (Kruskal-Wallis test, chi-squared = 79.83, $\mathrm{df}=11, P<0.001$, Fig. 3c, Post hoc differences Additional file 2: Table S3). The predatory myrmecophiles $S$. aterrimus, $T$. biovatus had individuals that forage at a very large distance from host nests (Figs. 3c,4, Additional file 1: Fig. S3), whereas the detritivorous species Monotoma, $C$. albinus and C. quadripuncta only travelled low to moderate distances (Fig. 3c, Additional file 1: Fig. S3).

\section{Co-movement of myrmecophiles and foraging red wood} ants

Myrmecophile species richness decreased away from the host nest (Fig. 4a, Table 2). Myrmecophile species richness was higher when more ants were present at a given distance outside the nest (host density as a categorical or continuous factor in Table 2, as a categorical factor in Fig. 4a). This implies that the myrmecophile community prefers to co-move with foraging host workers. This co-movement was clearly present in the predatory species $T$. biovatus and $S$. 
Table 1 Distribution of the myrmecophiles in the pitfalls (WV site). For each myrmecophile species, the number of captured individuals $\left(N_{\text {ind }}\right)$ and number of pitfalls with at least one individual $\left(N_{\text {pitfall }}\right)$ are summarized for intranidal pitfalls $(N=24)$, pitfalls at the periphery $(N=75)$, and pitfalls outside the nests $(>0 m, N=180)$

\begin{tabular}{|c|c|c|c|c|c|c|c|c|c|}
\hline \multirow[t]{2}{*}{ Species } & \multirow[t]{2}{*}{ Functional group } & \multirow[t]{2}{*}{ Taxon } & \multicolumn{2}{|c|}{$\begin{array}{l}\text { Intranidal } \\
\text { (24 pitfalls) }\end{array}$} & \multicolumn{2}{|c|}{$\begin{array}{l}\text { Periphery } \\
\text { (75 pitfalls) }\end{array}$} & \multicolumn{2}{|c|}{$\begin{array}{l}\text { Outside } \\
\text { (180 pitfalls) }\end{array}$} & \multirow[t]{2}{*}{$\begin{array}{l}\text { Total } \\
\text { records }\end{array}$} \\
\hline & & & $N_{\text {ind }}$ & $N_{\text {pitfall }}$ & $N_{\text {ind }}$ & $N_{\text {pitfall }}$ & $N_{\text {ind }}$ & $N_{\text {pitfall }}$ & \\
\hline Stenus aterrimus & predator & Coleoptera (Staphylinidae) & 22 & 10 & 467 & 53 & 152 & 30 & 641 \\
\hline Thyreosthenius biovatus & predator & Araneae (Linyphiidae) & 238 & 23 & 370 & 57 & 189 & 67 & 797 \\
\hline Thiasophila angulata & scavenger & Coleoptera (Staphylinidae) & 144 & 19 & 496 & 35 & 73 & 28 & 713 \\
\hline Lyprocorrhe anceps & scavenger & Coleoptera (Staphylinidae) & 45 & 10 & 565 & 49 & 113 & 59 & 723 \\
\hline Quedius brevis & scavenger & Coleoptera (Staphylinidae) & 1 & 1 & 16 & 12 & 24 & 10 & 41 \\
\hline Dinarda maerkelii & scavenger & Coleoptera (Staphylinidae) & 4 & 4 & 52 & 19 & 22 & 12 & 78 \\
\hline Notothecta flavipes & scavenger & Coleoptera (Staphylinidae) & 40 & 3 & 94 & 34 & 23 & 18 & 157 \\
\hline Amidobia talpa & scavenger & Coleoptera (Staphylinidae) & 2 & 1 & 25 & 11 & 7 & 5 & 34 \\
\hline Leptacinus formicetorum & scavenger & Coleoptera (Staphylinidae) & 1 & 1 & 0 & 0 & 1 & 1 & 2 \\
\hline Myrmetes paykulli & scavenger & Coleoptera (Histeridae) & 2 & 2 & 3 & 3 & 1 & 1 & 6 \\
\hline Pella humeralis & extranidal scavenger & Coleoptera (Staphylinidae) & 2 & 2 & 14 & 8 & 133 & 64 & 149 \\
\hline Monotoma & detritivore & Coleoptera (Monotomidae) & 518 & 19 & 140 & 33 & 6 & 5 & 664 \\
\hline Cyphoderus albinus & detritivore & Collembola (Cyphoderidae) & 416 & 15 & 184 & 35 & 27 & 15 & 627 \\
\hline Spavius glaber & detritivore & Coleoptera (Cryptophagidae) & 0 & 0 & 5 & 2 & 0 & 0 & 5 \\
\hline Platyarthrus hoffmannseggii & detritivore & Isopoda (Platyarthridae) & 9 & 1 & 51 & 3 & 0 & 0 & 60 \\
\hline Clytra quadripunctata & detritivore/parasite & Coleoptera (Chrysomelidae) & 286 & 23 & 176 & 31 & 7 & 5 & 469 \\
\hline
\end{tabular}

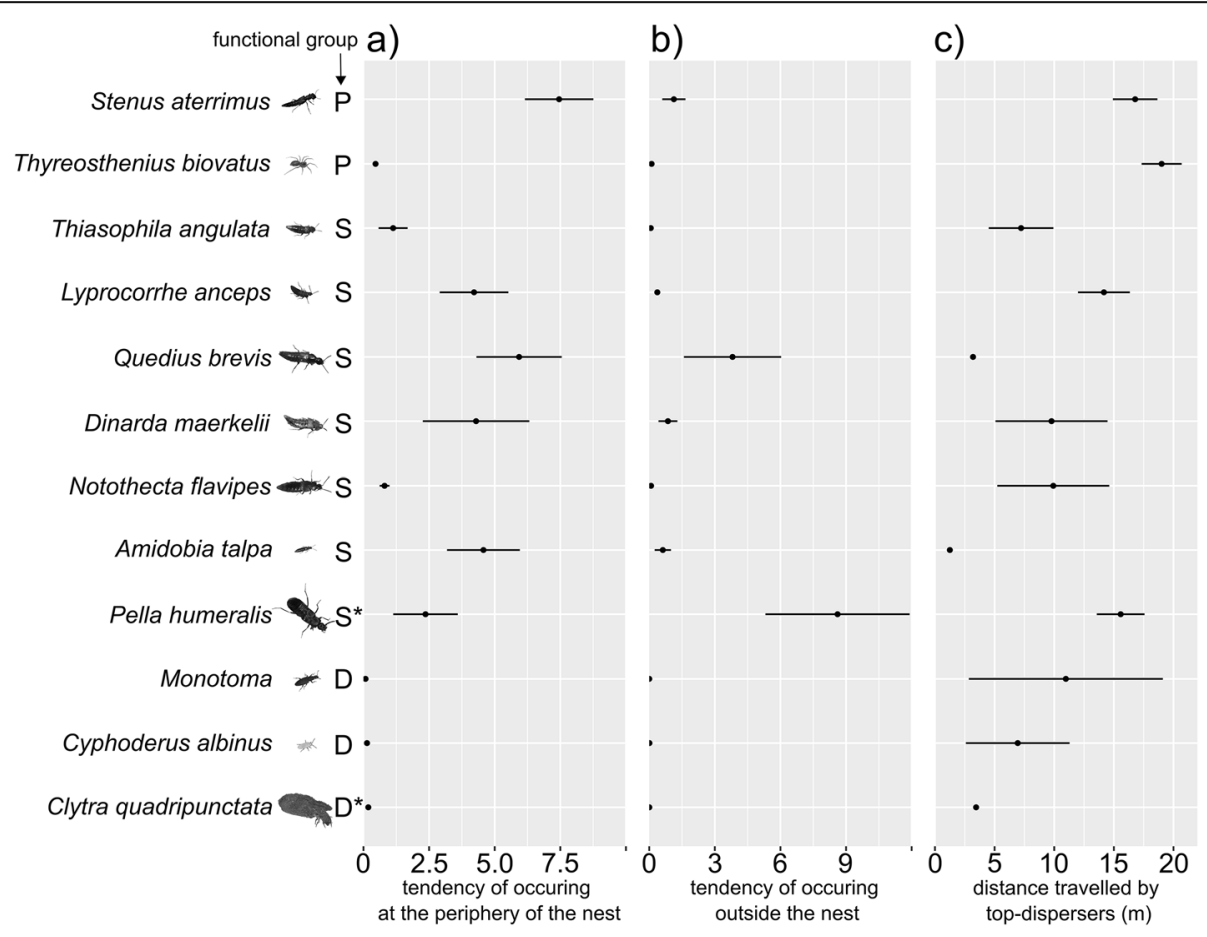

Fig. 3 Tendency of myrmecophiles associated with red wood ants to leave the nest. (a) Tendency of occurring at the periphery of the nest (abundance in a peripheral pitfall/abundance in an intranidal pitfall) (b) Tendency of occurring outside the nest (abundance in an outside pitfall/ abundance in an intranidal pitfall) (c) Mean distance travelled by the 10\% top dispersers for each species. Functional groups: P predator, S scavenger, $\mathrm{S}^{*}$ extranidal scavenger, $\mathrm{D}$ detritivore, $\mathrm{D}^{*}$ detritivore/parasite. Error bars indicate standard errors. Post hoc differences see Additional file 2: Table S1-3 


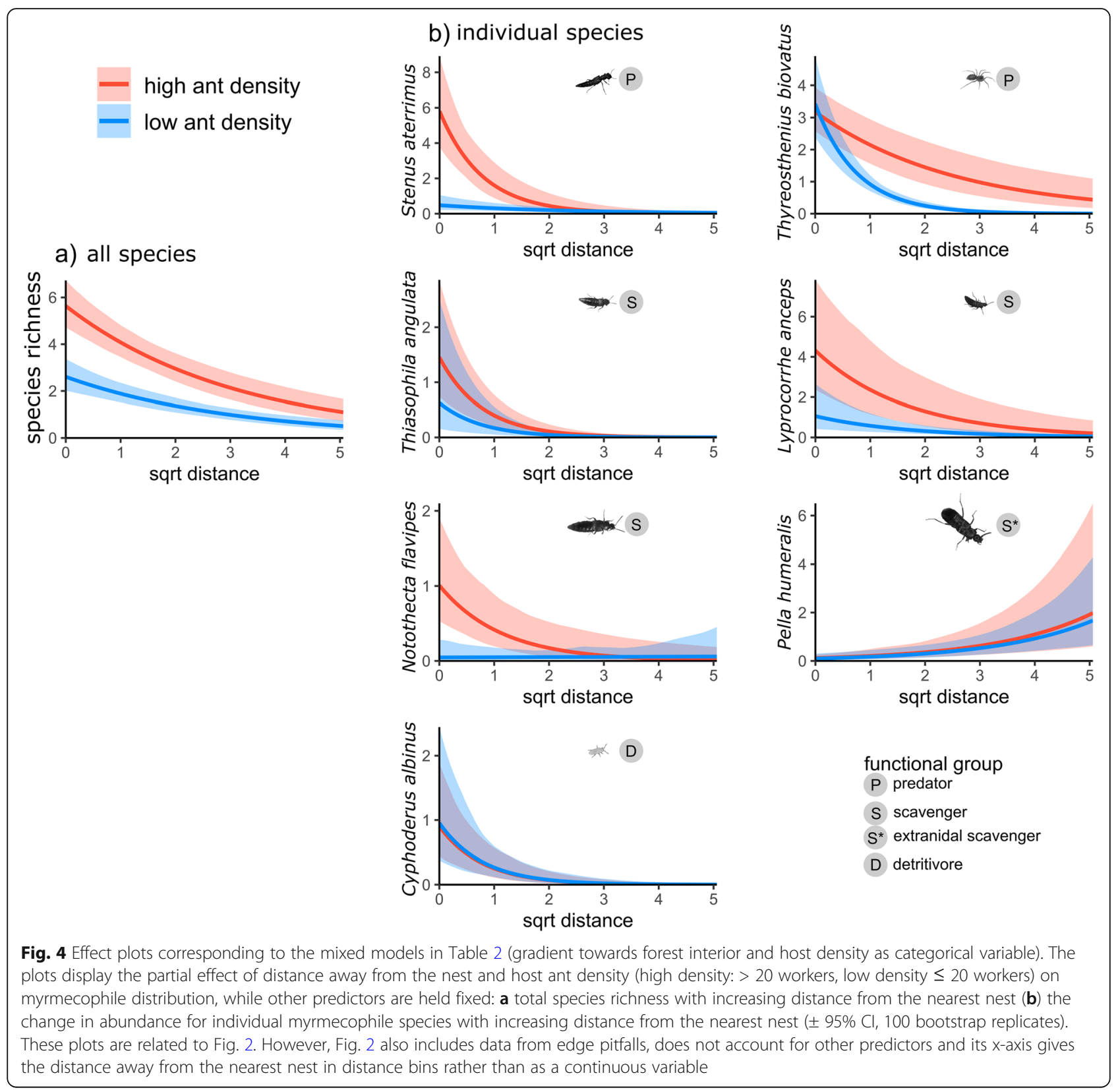

aterrimus, and in the scavenging species $T$. angulata, $L$. anceps and $N$. flavipes, as their individual distribution was positively correlated with the distribution of the host workers outside the nest (Fig. 4b, Table 2). The density of the detritivorous springtail C. albinus outside the nest was not correlated with higher host densities. Unlike other myrmecophiles, the density of $P$. humeralis increased away from the nest (Fig. 4b, Table 2). The number of individuals/species found outside the nest positively correlated with the number of myrmecophilous individuals found in a nest (or number of species in case of the species richness model) in multiple models (Table 2). Finally, a higher number of species was found towards the inner forest than along the forest edge (Table $2, P<0.001$ ).

\section{Colonization dynamics of myrmecophiles}

Newly founded nests supported fewer myrmecophile species than old nests (glmer.nb, $\mathrm{df}=1, x^{2}=50.3, P<$ 0.001 , Fig. 5). The difference in number of species between old and new nests (OB site: Post-hoc Tukey test: $P<0.001$; WV-site Post-hoc Tukey test: $P=0.09$ ) was higher in the site OB than in the WV-site (Fig. 5). Nest connectivity positively affected species richness, both in new and old nests (glmer.nb, $\mathrm{df}=1, \chi^{2}=7.8, P=0.005$ ). There was a lower likelihood to find myrmecophiles in 
Table 2 Test results of the factors affecting spatial distribution outside host nests in the WV site (Type 3 Wald $x^{2}$ tests)

\begin{tabular}{|c|c|c|c|c|c|c|c|c|c|}
\hline \multirow[t]{2}{*}{ Response variable } & \multirow[t]{2}{*}{ model } & \multirow[t]{2}{*}{ predictor } & \multirow[t]{2}{*}{ Df } & \multicolumn{3}{|c|}{$\begin{array}{l}\text { Host density } \\
\text { continuous }\end{array}$} & \multicolumn{3}{|c|}{$\begin{array}{l}\text { Host density categorical (low vs high } \\
\text { density) }\end{array}$} \\
\hline & & & & effect & $\mathrm{x}^{2}$ & $\mathbf{P}$ & effect & $\mathrm{x}^{2}$ & $P$ \\
\hline \multicolumn{10}{|c|}{ Gradient towards the forest interior } \\
\hline \multirow[t]{4}{*}{ Total species richness } & glmer & distance from nest & 1 & - & 47.5 & $<0.001$ & - & 54.9 & $<0.001$ \\
\hline & & host density & 1 & + & 19.4 & $<0.001$ & + & 39.2 & $<0.001$ \\
\hline & & number of species in the nest & 1 & + & 6.5 & 0.011 & + & 10.2 & 0.001 \\
\hline & & distance from nest $\mathrm{x}$ host density & 1 & + & 9.1 & 0.003 & & & \\
\hline \multirow[t]{4}{*}{ Number of Thyreosthenius } & glmer.nb & distance from nest & 1 & - & 36.5 & $<0.001$ & - & 10.2 & 0.001 \\
\hline & & host density & 1 & + & 3.9 & 0.049 & + & 0.0 & 0.84 \\
\hline & & number of individuals in the nest & 1 & + & 14.5 & $<0.001$ & + & 11.9 & $<0.001$ \\
\hline & & distance from nest $x$ host density & 1 & + & 15.5 & $<0.001$ & + & 15.8 & $<0.001$ \\
\hline \multirow[t]{3}{*}{ Number of Stenus } & glmer.nb & distance from nest & 1 & - & 25.7 & $<0.001$ & - & 33.5 & $<0.001$ \\
\hline & & host density & 1 & + & 16.0 & $<0.001$ & + & 26.2 & $<0.001$ \\
\hline & & distance from nest $x$ host density & & & & & - & 11.8 & $<0.001$ \\
\hline \multirow[t]{3}{*}{ Number of Thiasophila } & glmer.nb & distance from nest & 1 & - & 31.4 & $<0.001$ & - & 38.1 & $<0.001$ \\
\hline & & host density & 1 & + & 10.6 & 0.001 & + & 3.4 & 0.07 \\
\hline & & number of individuals in the nest & 1 & + & 11.4 & $<0.001$ & & & \\
\hline \multirow[t]{2}{*}{ Number of Lyprocorrhe } & glmer.nb & distance from nest & 1 & - & 20.7 & $<0.001$ & - & 23.0 & $<0.001$ \\
\hline & & host density & 1 & + & 22.5 & $<0.001$ & + & 13.4 & $<0.001$ \\
\hline \multirow[t]{4}{*}{ Number of Notothecta } & glmer.nb & distance from nest & 1 & - & 8.7 & 0.003 & - & 11.3 & $<0.001$ \\
\hline & & host density & 1 & + & 18.2 & $<0.001$ & + & 13.6 & $<0.001$ \\
\hline & & number of individuals in the nest & & & & & + & 3.2 & 0.072 \\
\hline & & distance from nest $\mathrm{x}$ host density & & & & & - & 5.6 & 0.018 \\
\hline Number of Pella & glmer.nb & distance from nest & 1 & + & 24.9 & $<0.001$ & + & 24.9 & $<0.001$ \\
\hline \multirow[t]{2}{*}{ Number of Cyphoderus } & glmer.nb & distance from nest & 1 & - & 36.0 & $<0.001$ & - & 36.0 & $<0.001$ \\
\hline & & number of individuals in the nest & 1 & + & 3.7 & 0.06 & + & 3.7 & 0.06 \\
\hline \multicolumn{10}{|l|}{ Gradient forest vs edge } \\
\hline \multirow[t]{3}{*}{ Total species richness } & glmer & directionality of movement & 1 & - & 14.7 & $<0.001$ & & 6.1 & 0.013 \\
\hline & & distance from nest & 1 & + & 6.8 & 0.010 & - & 8.5 & 0.003 \\
\hline & & host density & 1 & + & 31.8 & $<0.001$ & + & 9.7 & 0.002 \\
\hline
\end{tabular}

new nests. The proportion of new and old nests colonized by each species is given in Fig. 6. The density of myrmecophile populations, and especially in the OB-site, was mostly lower in new nests (for each species, bar lengths proportional to mean abundance in Fig. 6). However, almost all myrmecophile species were able to colonize new nests in the first months after they were founded (Fig. 6). Only Dinarda maerkelii, Quedius brevis and Mastigusa arietina were not recorded in the new nests, but these species were also caught in very low numbers in old nests.

\section{Discussion}

We found a remarkably high number of intranidal ant symbionts or myrmecophiles outside their host nest. We showed that these tightly connected ant symbiont communities are also connected during movement, by following the movement of their shared host. There was heterogeneous variation among symbiont groups which was linked to their functional role in the community. Assembly processes in new patches could not be directly connected to these differences in mobility.

The majority of ant species are central-place foragers which construct permanent nests [58]. Myrmecophiles obligately living in the nest of these ants are only sporadically reported outside the host nest $[10,36-40,59]$ and are typically collected by opening the nest. Red wood ant (RWA) myrmecophiles of this study have been occasionally recorded outside the nest using pitfalls or hand capture: T. angulata [38, 60], T. biovatus [61-63], P. hoffmannseggii [64, 65], N. flavipes [66, 67], S. aterrimus: [67], A. talpa [67], Q. brevis [66], M. paykulli [68], 


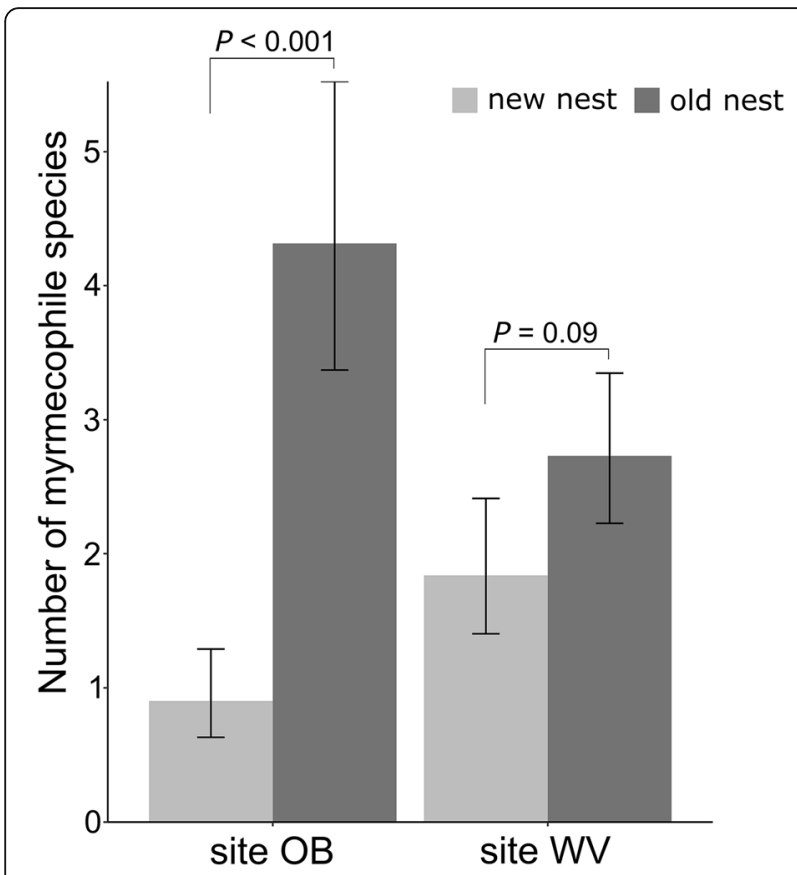

Fig. 5 Effect plot showing the partial effect of nest age on species richness $( \pm 95 \% \mathrm{Cl})$ for site OB and site $\mathrm{W}$ while the predictor connectivity in the model is held fixed. Old nests hold higher number of species than new nests for a given level of connectivity, but this effect was clearer in the OB-site

but they have always been reported in very small numbers (max. five individuals) (cfr. their large densities inside RWA nests [69]). The large number of records outside the nest, and including all members of the studied community, here is therefore unexpected and very novel. The records of myrmecophiles associated with other permanent ant nests often seemed to be linked to specific events in the host colony life cycle (e.g. [10]). Some myrmecophile species were recorded when they followed their host colony moving to a new nest site [39]. Flying Paussus beetles are captured using light pitfalls and in increased numbers at the beginning of the rains, coinciding with the host's nuptial flights [70]. The high extranidal mobility found in the RWA myrmecophile community, by contrast, was found all summer and probably spans from spring to autumn. It should be noted that high mobility is known in the peculiar group of myrmecophiles associated with nomadic army ants. These ants do not construct permanent nests and are almost incessantly on the move [71]. Consequently, there is a high selection pressure on the associated myrmecophile fauna to keep pace with the very mobile host colony. They mainly achieve this by running independently among the moving ants on the trails or by phoretic transport [71, 72].

Species in the myrmecophile community greatly differed in their tendency to exit the nest and the distance they travelled away from the host nest. The extranidal mobility was strongly correlated with their functional role. Detritivorous species were more restricted to the host nest than predatory species. Moreover, leaving individuals of detritivores stayed closer to the nest than those of predatory species. Differential mobility among competing species may result in a competition-colonization trade-off, which promotes the community assembly of regular metacommunities [73], but also of symbiont communities (e.g. [58]). However, species that compete for the same food sources in the myrmecophile system tend to have similar degrees of mobility. It is unclear whether the high mobility of predatory species is translated into superior dispersal capacities. It is possible that the predatory species leave the nest to hunt for prey and return. The rove beetle Pella humeralis showed a deviating spatial distribution. It was rarely found in or near the nest, but was the dominant myrmecophile at greater distances away from the nest. Other studies showed that this species and congeners frequently dwell around ant nests [58, 74].

Organisms move non-randomly in the landscape and they often prefer certain routes to move from one patch to another, as evidenced in insects [75], amphibians [76], birds [77] and mammals [78]. Likewise, the myrmecophile community associated with RWAs did show directed movement outside the nest. They preferentially moved along the highest density of ants outside the nest (such as along trails) and avoided the forest edge. Central-place foraging ants often deploy a network of pheromone trails radiating out to food sources [58], and this web of trails is especially well developed in RWAs $[47,79]$. Lab experiments demonstrated that pheromone trails of ants may be followed by symbionts [41-45]. Here, we found that RWA myrmecophiles likely exploit these cues to co-move in the landscape in a natural setting. Running among large numbers of workers offers the myrmecophiles protection against predators. The RWA myrmecophiles can flexibly shift between foraging, dispersal or escaping from enemies as they do not comove attached to a vector species. Ant trails may also guide myrmecophiles to extranidal food sources or lead them to new nests as trails may overlap or connect different nests [47]. The denser network of ant trails and the polydomous organization with inter-nest trails in the WV site may have resulted in a faster colonization of newly founded nests compared to the OB site. Movement was also directed away from the forest edges. These edges are characterized by higher temperature fluctuations, higher light levels, reduced moisture and increased predation [80]. The higher stress at the edge may explain the preferential movement of the myrmecophiles away from the edge. 


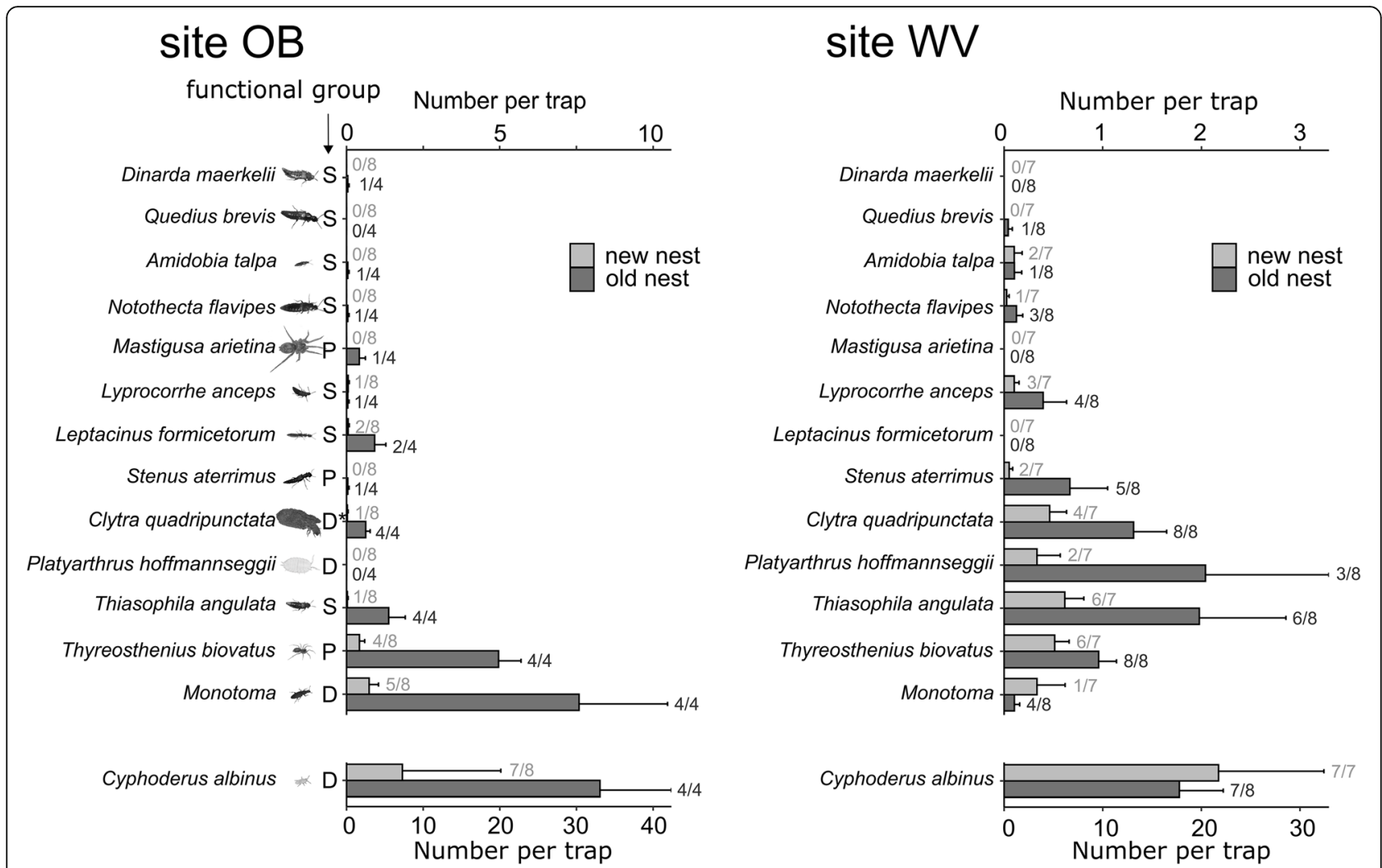

Fig. 6 Average abundance \pm SE of myrmecophile species found using wood chip pitfalls in new and old nests in the $O B\left(N_{\text {new }}=8 N_{\text {old }}=4\right)$ and $W$-site $\left(N_{\text {new }}=7 N_{\text {old }}=8\right)$. Cyphoderus albinus average abundance per trap given on lower axis, abundances of other myrmecophiles given on the top-axis. Functional groups: P predator, S scavenger, D detritivore, $\mathrm{D}^{*}$ detritivore/parasite. The proportion of new and old nests where the myrmecophile species was found at least once (each nest was sampled four to six times) is given to the right of the average abundance bars

The process of colonization and succession of new habitat patches (habitat islands) reveals how communities may adapt to fluctuating patch availability and assemble over time. Host-symbiont communities provide ideal microcosms to track colonization in natural settings [81]. We tracked for the first time colonization of newly emerged ant nests by symbionts. In line with theoretical and empirical studies, we found lower diversity in newly founded nests than in mature nests [82-84]. Most myrmecophiles were able to colonize a new nest within the first months, but the lower observed diversity indicate that the associated communities did not reach an equilibrium, yet. The weakly mobile myrmecophiles C. albinus and Monotoma beetles surprisingly colonized most new nests and even reached the highest densities of the newly assembled communities. This discrepancy between extranidal motility and colonization can be caused by different processes. A few myrmecophilous species, such as the springtail $C$. albinus, target other ant hosts scattered over the study site, as well. These species can use nests of other ant species as stepping stones to colonize new RWA nests. This process could explain why $C$. albinus was able to rapidly colonize even the most isolated new RWA nest (400 m away from the nearest RWA nest). Another explanation is that the densities of myrmecophiles in new nests do not reflect the number of successful colonization events. It is possible that a few colonizers may reproduce rapidly. Furthermore, high extranidal mobility as observed in $S$. aterrimus and $T$. biovatus may be linked to foraging rather than to dispersing events. Lastly, the community has other modes of dispersing than running. One species, the larvae of the beetle Clytra quadripunctata, may be carried by the host from one nest to another [39]. But more crucially, a large part of the community has functional wings. Flying has rarely been recorded in this community [49], and aerial dispersal is probably restricted to a narrow time frame in their life cycle or limited to particular seasonal conditions. This was also suggested by [38] who found that newly emerged Thiasophila beetles associated with RWAs were attracted to light and attempted to fly off. After 2 weeks, the beetles did no longer show attempts to fly, avoided light and mostly hid in the nest material. Overall, the relative importance of flying dispersal compared to dispersal by walking is unclear in this community. 


\section{Conclusions}

Future research may further elaborate this neat hostsymbiont system and address fundamental ecological questions, such as assessing the relative role of local and regional processes in assembling metacommunities, and testing the effect of (co-)dispersal on the stability of the communities and food webs. Much theory on metacommunities and metafoodwebs were derived from the results of lab microcosms, but extending our focus to natural metacommunities, and in which the movement of a species might be directly or indirectly affected by other species, could start to fill the gap in our understanding of the dynamics of realistic metacommunities.

\section{Supplementary Information}

The online version contains supplementary material available at https://doi. org/10.1186/s40462-021-00259-5.

Additional file 1: Supporting Figs. S1, S2 and S3. S1. Map of red wood ant nest distribution in site WW and site OB. S2: Overview of the sampling of the myrmecophiles. S3: Relative abundances of the 12 most widely distributed myrmecophile species along the spatial gradient.

Additional file 2: Supporting tables Table S1-S3. Listing the Posthoc test results related to Fig. 3 .

Additional file 3: Video featuring a pitfall near a wood ant nest.

\section{Acknowledgements}

We thank the Flemish Agency for Nature and Forest (ANB) for granting permission to sample at their sites.

\section{Authors' contributions}

TP conceived the ideas and designed methodology; TP, RC collected the data; All authors analysed the data; TP led the writing of the manuscript. All authors contributed critically to the drafts and gave final approval for publication.

\section{Funding}

This work was supported by FWO and FNRS (1203020 N/30257865 to TP).

\section{Availability of data and materials}

Datasets can be accessed at https://github.com/tjparmen/Moving-aparttogether-co-movement-of-a-symbiont-community-and-their-ant-host.

\section{Declarations}

Ethics approval and consent to participate

Not applicable.

\section{Consent for publication}

Not applicable.

\section{Competing interests}

The authors declare that they have no competing interests.

Received: 18 December 2020 Accepted: 1 April 2021

Published online: 21 May 2021

\section{References}

1. Barabás G, D'Andrea R, Stump SM. Chesson's coexistence theory. Ecol Monogr. 2018;88(3):277-303. https://doi.org/10.1002/ecm.1302.

2. Spaak JW, De Laender F. Intuitive and broadly applicable definitions of niche and fitness differences. Ecol Lett. 2020;23(7):1117-28. https://doi.org/1 0.1111/ele.13511.

3. Jeltsch F, Bonte $D, P^{\prime} E r G$, Reineking $B$, Leimgruber $P$, Balkenhol $N$, et al. Integrating movement ecology with biodiversity research - exploring new avenues to address spatiotemporal biodiversity dynamics. Mov Ecol. 2013;1: $1-13$.

4. Bonte D, Van Dyck H, Bullock JM, Coulon A, Delgado M, Gibbs M, et al. Costs of dispersal. Biol Rev. 2012;87(2):290-312. https://doi.org/10.1111/j.14 69-185X.2011.00201.X.

5. Fronhofer EA, Legrand D, Altermatt F, Ansart A, Blanchet S, Bonte D, et al. Bottom-up and top-down control of dispersal across major organismal groups. Nat Ecol Evol. 2018;2(12):1859-63. https://doi.org/10.1038/s41559-01 8-0686-0.

6. Kivelä SM, Seppänen JT, Ovaskainen O, Doligez B, Gustafsson L, Mönkkönen $M$, et al. The past and the present in decision-making: the use of conspecific and heterospecific cues in nest site selection. Ecology. 2014; 95(12):3428-39. https://doi.org/10.1890/13-2103.1.

7. Fronhofer EA, Sperr EB, Kreis A, Ayasse M, Poethke HJ, Tschapka M. Picky hitch-hikers: vector choice leads to directed dispersal and fat-tailed kernels in a passively dispersing mite. Oikos. 2013;122(8):1254-64. https://doi.org/1 0.1111/j.1600-0706.2013.00503.x.

8. Viana DS, Santamaría L, Figuerola J. Migratory birds as global dispersal vectors. Trends Ecol Evol. 2016;31(10):763-75. https://doi.org/10.1016/j.tree.2 016.07.005

9. Pettay DT, Lajeunesse TC. Long-range dispersal and high-latitude environments influence the population structure of a "stress-tolerant" dinoflagellate endosymbiont. 2013;8:1-12.

10. Phillips Zl, Zhang MM, Mueller UG. Dispersal of Attaphila fungicola, a symbiotic cockroach of leaf-cutter ants. Insect Soc. 2017;64(2):277-84. https://doi.org/10.1007/s00040-016-0535-6.

11. Poulsen $\mathrm{M}$, Boomsma JJ. Mutualistic fungi control crop diversity in fungusgrowing ants. Science. 2005;307(5710):741-4. https://doi.org/10.1126/ science. 1106688

12. Wornik S, Grube M. Joint dispersal does not imply maintenance of partnerships in lichen symbioses. Microb Ecol. 2010;59(1):150-7. https://doi. org/10.1007/s00248-009-9584-y.

13. Zhang Y, Kastman EK, Guasto JS, Wolfe BE. Fungal networks shape dynamics of bacterial dispersal and community assembly in cheese rind microbiomes. Nat Commun. 2018;9:1-12

14. Lukoschek V, McCormick Ml. A review of multi-species foraging associations in fishes and their ecological significance. Proc Ninth Int Coral Reef Symp. 2000; (October 23-27):467-74.

15. Strand S. Following behavior: interspecific foraging associations among Gulf of California reef fishes. Copeia. 1988;1988(2):351-7. https://doi.org/10.23 07/1445875.

16. Silverman ED, Veit RR, Nevitt GA. Nearest neighbors as foraging cues: information transfer in a patchy environment. Mar Ecol Prog Ser. 2004;277: 25-35. https://doi.org/10.3354/meps277025

17. Morse $\mathrm{DH}$. Ecological aspects of some mixed-species foraging flocks of birds. Ecol Monogr. 1970;40(1):119-68. https://doi.org/10.2307/1942443.

18. Sharpe LL, Joustra AS, Cherry MI. The presence of an avian co-forager reduces vigilance in a cooperative mammal. Biol Lett. 2010;6(4):475-7. https://doi.org/10.1098/rsbl.2009.1016.

19. Bunnefeld L, Hearn J, Stone GN, Lohse K. Whole-genome data reveal the complex history of a diverse ecological community. Proc Natl Acad Sci U S A. 2018;115(28):E6507-15. https://doi.org/10.1073/pnas.1800334115.

20. Bonte D, Dahirel M. Dispersal: a central and independent trait in life history. Oikos. 2017;126(4):472-9. https://doi.org/10.1111/oik.03801.

21. Goodale E, Beauchamp G, Magrath RD, Nieh JC, Ruxton GD. Interspecific information transfer influences animal community structure. Trends Ecol Evol. 2010;25(6):354-61. https://doi.org/10.1016/j.tree.2010.01.002.

22. Bitume EV, Bonte D, Ronce O, Bach F, Flaven E, Olivieri I, et al. Density and genetic relatedness increase dispersal distance in a subsocial organism. Ecol Lett. 2013:16(4):430-7. https://doi.org/10.1111/ele.12057.

23. Travis JMJ, Delgado M, Bocedi G, Baguette M, Bartoń K, Bonte D, et al. Dispersal and species' responses to climate change. Oikos. 2013;122(11): 1532-40. https://doi.org/10.1111/j.1600-0706.2013.00399.x.

24. Snyder RE, Chesson P. Local dispersal can facilitate coexistence in the presence of permanent spatial heterogeneity. Ecol Lett. 2003;6(4):301-9. https://doi.org/10.1046/j.1461-0248.2003.00434.x.

25. Parmentier T. Guests of social insects. In: Starr CK, editor. Encyclopaedia of social insects. Springer, Cham; 2020, Guests of Social Insects.

26. Parmentier T, Bouillon S, Dekoninck W, Wenseleers T. Trophic interactions in an ant nest microcosm: a combined experimental and stable isotope $(\delta 13 \mathrm{Cl}$ 815N) approach. Oikos. 2016;125(8):1182-92. https://doi.org/10.1111/oik.02991. 
27. Maruyama M, Parker J. Deep-time parallel evolution of myrmecoid syndrome in rove beetle symbionts of army ants. Curr Biol. 2017;27(6):9206. https://doi.org/10.1016/j.cub.2017.02.030.

28. Nash DR, Als TD, Maile R, Jones GR, Boomsma JJ. A mosaic of chemical coevolution in a large blue butterfly. Science. 2008;319(5859):88-90. https:// doi.org/10.1126/science.1149180.

29. Lachaud J-P, Pérez-Lachaud G. Diversity of species and behavior of hymenopteran parasitoids of ants: a review. Psyche A J Entomol. 2012:1-24.

30. Parmentier T, Dekoninck W, Wenseleers T. Do well-integrated species of an inquiline community have a lower brood predation tendency? A test using red wood ant myrmecophiles. BMC Evol Biol. 2016;16(1):12. https://doi.org/1 0.1186/s12862-016-0583-6.

31. von Beeren $C$, Maruyama M, Hashim $R$, Witte $V$. Differential host defense against multiple parasites in ants. Evol Ecol. 2011;25(2):259-76. https://doi. org/10.1007/s10682-010-9420-3.

32. Ivens ABF, Von Beeren C, BI N, Kronauer DJC. Studying the complex communities of ants and their symbionts using ecological network analysis. Annu Rev Entomol. 2016;61(1):353-71. https://doi.org/10.1146/annurev-ento010715-023719.

33. Parmentier T, Dekoninck W, Wenseleers T. Metapopulation processes affecting diversity and distribution of myrmecophiles associated with red wood ants. Basic Appl Ecol. 2015;16(6):553-62. https://doi.org/10.1016/j.baa e.2015.04.008.

34. Härkönen SK, Sorvari J. Species richness of associates of ants in the nests of red wood ant Formica polyctena (Hymenoptera, Formicidae). Insect Conserv Divers. 2014;7(6):485-95. https://doi.org/10.1111/icad.12072

35. Leibold MA, Holyoak M, Mouquet N, Amarasekare P, Chase JM, Hoopes MF, et al. The metacommunity concept: a framework for multi-scale community ecology. Ecol Lett. 2004;7(7):601-13. https://doi.org/10.1111/j.1461-0248.2 004.00608.x

36. Donisthorpe HSJK. The guests of British ants, their habits and life-histories. London: George Routledge and Sons; 1927. 244 p.

37. Ichinose K, Rinaldi I, Forti LC. Winged leaf-cutting ants on nuptial flights used as transport by Attacobius spiders for dispersal. Ecol Entomol. 2004; 29(5):628-31. https://doi.org/10.1111/j.0307-6946.2004.00640.x.

38. Zagaja M, Staniec B, Pietrykowska-Tudruj E, Trytek M. Biology and defensive secretion of myrmecophilous Thiasophila spp. (Coleoptera: Staphylinidae: Aleocharinae) associated with the Formica rufa species group. J Nat Hist. 2017;51(45-46):2759-77. https://doi.org/10.1080/00222933.2017.1387299.

39. Parmentier T. Host following of an ant associate during nest relocation. Insect Soc. 2019;66(2):329-32. https://doi.org/10.1007/s00040-019-00688-x.

40. Maruyama M. The guests of Japanese ants: Tokai University Press; 2013.

41. Dejean A, Beugnon G. Host-ant trail following by myrmecophilous larvae of Liphyrinae (Lepidoptera, Lycaenidae). Oecologia. 1996;106(1):57-62. https:// doi.org/10.1007/BF00334407.

42. Lenoir A, Detrain C, Barbazanges N. Host trail following by the guest ant Formicoxenus provancheri. Experientia. 1992:48:95-7.

43. Cammaerts R, Detrain C, Cammaerts M-C. Host trail following by the myrmecophilous beetle Edaphopaussus favieri (fairmaire) (Carabidae Paussinae). Insect Soc. 1990;37(3):200-11. https://doi.org/10.1007/BF02224048.

44. Akino T, Yamaoka R. Chemical mimicry in the root aphid parasitoid Paralipsis eikoae Yasumatsu (Hymenoptera: Aphidiidae) of the aphidattending ant Lasius sakagamii/ Yamauchi \& Hayashida (Hymenoptera: Formicidae). Chemoecology. 1998;8(4):153-61. https://doi.org/10.1007/s0004 90050020 .

45. Akino T. Chemical camouflage by myrmecophilous beetles Zyras comes (Coleoptera: Staphylinidae) and Diaritiger fossulatus (Coleoptera: Pselaphidae) to be integrated into the nest of Lasius fuliginosus (Hymenoptera: Formicidae). Chemoecology. 2002;12(2):83-9. https://doi. org/10.1007/s00049-002-8330-4

46. Stockan JA, EJH R. Wood ant ecology and conservation: Cambridge University Press; 2016

47. Burns DDR, Franks DW, Parr C, Robinson EJH. Ant colony nest networks adapt to resource disruption. J Anim Ecol. 2020:90:143-52.

48. Parmentier T, Dekoninck W, Wenseleers T. A highly diverse microcosm in a hostile world: a review on the associates of red wood ants (Formica rufa group). Insect Soc 2014;61(3):229-37. https://doi.org/10.1007/s00040-014-0357-3.

49. Parmentier T. Conflict and cooperation between ants and ant-associated arthropods. Kuleuven: PhD thesis; 2016. p. 268.

50. Seifert B. Die Ameisen Mittel- und Nordeuropas. Görlitz: lutra Verlags- und Vertriebsgesellschaft, 368; 2007
51. Parmentier T, Dekoninck W, Wenseleers T. Arthropods associate with their red wood ant host without matching nestmate recognition cues. J Chem Ecol. 2017;43(7):644-61. https://doi.org/10.1007/s10886-017-0868-2.

52. Freude H, Harde KW, Lohse GA. Käfer Mitteleuropas Bd 4. Staphylinidae I (Micropeplinae bis Tachyporinae). Krefeld: Goecke et Evers Verlag; 1964. 264 p.

53. Freude H, Harde KW, Lohse GA. Käfer Mitteleuropas. Bd 5. Staphylinidae II (Hypocyphtinae und Aleocharinae), Pselaphidae. Krefeld: Goecke et Evers Verlag; 1974. 381 p.

54. Roberts M. Spiders of Britain and northern Europe (Collins field guide): Harpercollins Pub Ltd; 2001. p. 320.

55. Benjamini $Y$, Hochberg $Y$. Controlling the false discovery rate: a practical and powerful approach to multiple testing. J R Stat Soc B. 1995;57:289-300.

56. Crawley MJ. The R Book. 2007.

57. Hartig F. DHARMa: residual diagnostics for hierarchical regression models: The Comprehensive R Archive Network; 2020.

58. Hölldobler B, Wilson EO. The ants. Cambridge, Massachusetts: Harvard University Press; 1990. https://doi.org/10.1007/978-3-662-10306-7.

59. Sautiere C, Calmont B, Coache A. Amorcephala coronata (Germar, 1817): sa découverte en Ardèche et point sur sa répartition en France (Coleoptera Brentidae). L'Entomologiste. 2012;68:117-22.

60. Wolender M, Zych A. Beetles (Coleoptera) from seaside beach and dunes in the regions of Świnoujście, Międzyzdroje and Wisełka (Poland) located along the southern coast of the Baltic Sea. Balt J Coleopt. 2007:7:61-71.

61. Dekoninck W, Van Kerckvoorde M, Van Nieuwenhuyse L, Parmentier T, Baert L. De spinnenfauna van enkele Rode dopheidegebieden nabij Brugge: Deel 2: Bemonsteringen in Provinciedomein Tillegembos in 2015-2016. Nieuwsbr Belgische Arachnol Ver. 2019;34:116-27.

62. Höfer H, Meyer F, Bauer T, Bayer S, Harry I, Kastner L. Überraschende Erstnachweise und neue Daten zu seltenen Spinnenarten (Arachnida: Araneae) aus Blockhalden in Baden-Württemberg. Arachnol Mitt. 2019;58(1): 62-84. https://doi.org/10.30963/aramit5811.

63. Gajdos P. Research on epigeic spider communities in agriciltural landscape of Malanta (south-West Slovakia). The experimental area with alternative cultivation. Boll Acc Gioenia Sci Nat. 1993:26:135-44.

64. Farkas S, Krcmar S. Terrestrial isopods (Isopoda : Oniscidea) of Baranya (Croatia). Nat Croat. 2004:13:161-70

65. Riedel P, Navrátil M, Tuf IH, Tufová J. Terrestrial isopods (Isopoda : Oniscidea) and millipedes (Diplopoda) of the City of Olomouc (Czech Republic). Contrib to soil Zool Cent Eur III. 2007:17-2.

66. Siitonen J. Faunistic records of Carabidae and Staphylinidae (Coleoptera) caught by pitfall trapping in western Finnish Lapland. Entomol Fenn. 1993; 4(4):225-31. https://doi.org/10.33338/ef.83774.

67. Roosileht U. Estonian additions to Silfverberg's " Enumeratio renovata Coleopterorum Fennoscandiae, Daniae et Baltiae" Coleoptera catalog. Sahlbergia. 2015;2:6-39.

68. Telnov D, Gailis J, Kalninš M, Napolov A, Piterans U, Vilks K, et al. Contributions to the knowledge of Latvian Coleoptera. 4. Latv. Entomol. 2005;42:18-47.

69. Parmentier T. A dazzling number of beetles (Coleoptera) in a hibernating nest of red wood ants, Formica rufa Linnaeus. Coleopt Bull. 2019;73:1-4.

70. Geiselhardt SF, Peschke K, Nagel P. A review of myrmecophily in ant nest beetles (Coleoptera: Carabidae: Paussinae): linking early observations with recent findings. Naturwissenschaften. 2007;94(11):871-94. https://doi.org/1 0.1007/s00114-007-0271-x.

71. Kronauer DJC. Army ants: nature's ultimate social hunters: Harvard University Press; 2020. https://doi.org/10.4159/9780674249417.

72. Akre RD, Rettenmeyer CW. Trail-following by quests of army ants (Hymenoptera: Formicidae: Ecitonini). J Kansas Entomol Soc. 1968;41:165-74.

73. Cadotte MW, Mai DV, Jantz S, Collins MD. On testing the competitioncolonization trade-off in a multispecies assemblage. Am Nat. 2014;168:704-9.

74. Thunes KH, Gjerde I, Skartveit J. The red wood ant Formica aquilonia (Hymenoptera : Formicidae) may affect both local species richness and composition at multiple trophic levels in a boreal forest ecosystem. Ann Zool Fenn. 2018:55(4-6):159-72. https://doi.org/10.5735/086.055.0603.

75. Berggren $\AA$, Birath B, Kindvall O. Effect of corridors and habitat edges on dispersal behavior, movement rates, and movement angles in Roesel's bush-cricket (Metrioptera roeseli). Conserv Biol. 2002;16(6):1562-9. https://doi. org/10.1046/j.1523-1739.2002.01203.x.

76. Wang IJ, Savage WK, Schaffer HB. Landscape genetics and least-cost path analysis reveal unexpected dispersal routes in the California tiger salamander (Ambystoma californiense). Mol Biol Evol. 2009;18:1365-74. 
77. Haas CA. Dispersal and use of corridors by birds in wooded patches on an agricultural landscape. Conserv Biol. 1995;9(4):845-54. https://doi.org/10.104 6/j.1523-1739.1995.09040845.x.

78. Hansson L. Dispersal routes of small mammals at an abandoned field in Central Sweden. Holarct Ecol. 1987;10:154-9.

79. Buhl J, Hicks K, Miller ER, Persey S, Alinvi O, Sumpter DJT. Shape and efficiency of wood ant foraging networks. Behav Ecol Sociobiol. 2009;63(3): 451-60. https://doi.org/10.1007/s00265-008-0680-7.

80. Murcia C. Edge effects in fragmented forests: implications for conservation. Trends Ecol Evol. 1995;10(2):58-62. https://doi.org/10.1016/50169-534 7(00)88977-6.

81. Boynton PJ, Peterson CN, Pringle A. Superior dispersal ability can lead to persistent ecological dominance throughout succession. Appl Environ Microbiol. 2019;85:e02421-18.

82. Letcher SG, Chazdon RL. Rapid recovery of biomass, species richness, and species composition in a forest chronosequence in northeastern Costa Rica. Biotropica. 2009;41(5):608-17. https://doi.org/10.1111/j.1744-7429.2009.00517.x.

83. Sø JS, Sand-Jensen K, Baastrup-Spohr L. Temporal development of biodiversity of macrophytes in newly established lakes. Freshw Biol. 2020;65: 379-89.

84. Odum EP. The strategy of ecosystem development. Science. 1969;164(3877): 262-70. https://doi.org/10.1126/science.164.3877.262.

\section{Publisher's Note}

Springer Nature remains neutral with regard to jurisdictional claims in published maps and institutional affiliations.

Ready to submit your research? Choose BMC and benefit from:

- fast, convenient online submission

- thorough peer review by experienced researchers in your field

- rapid publication on acceptance

- support for research data, including large and complex data types

- gold Open Access which fosters wider collaboration and increased citations

- maximum visibility for your research: over $100 \mathrm{M}$ website views per year

At BMC, research is always in progress.

Learn more biomedcentral.com/submissions 